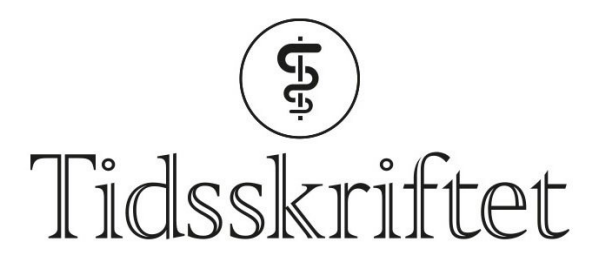

DEN NORSKE LEGEFORENING

\title{
Da spanskesyken kom til Andøya
}

ESSAY

\section{MORTEN SANDBU}

E-post: morten.sandbu@gmail.com

Morten Sandbu er overlege ved Regional seksjon for spiseforstyrrelser ved Oslo universitetssykehus. Forfatteren har fylt ut ICMJE-skjemaet og oppgir ingen interessekonflikter.

I juli 1918 kom spanskesyken til Andøya. Kommunelege Christian Fredrik Rossow nedtegnet sine erfaringer med epidemien. Hans beskrivelser har klare likhetstrekk med dagens covid-19-epidemi.

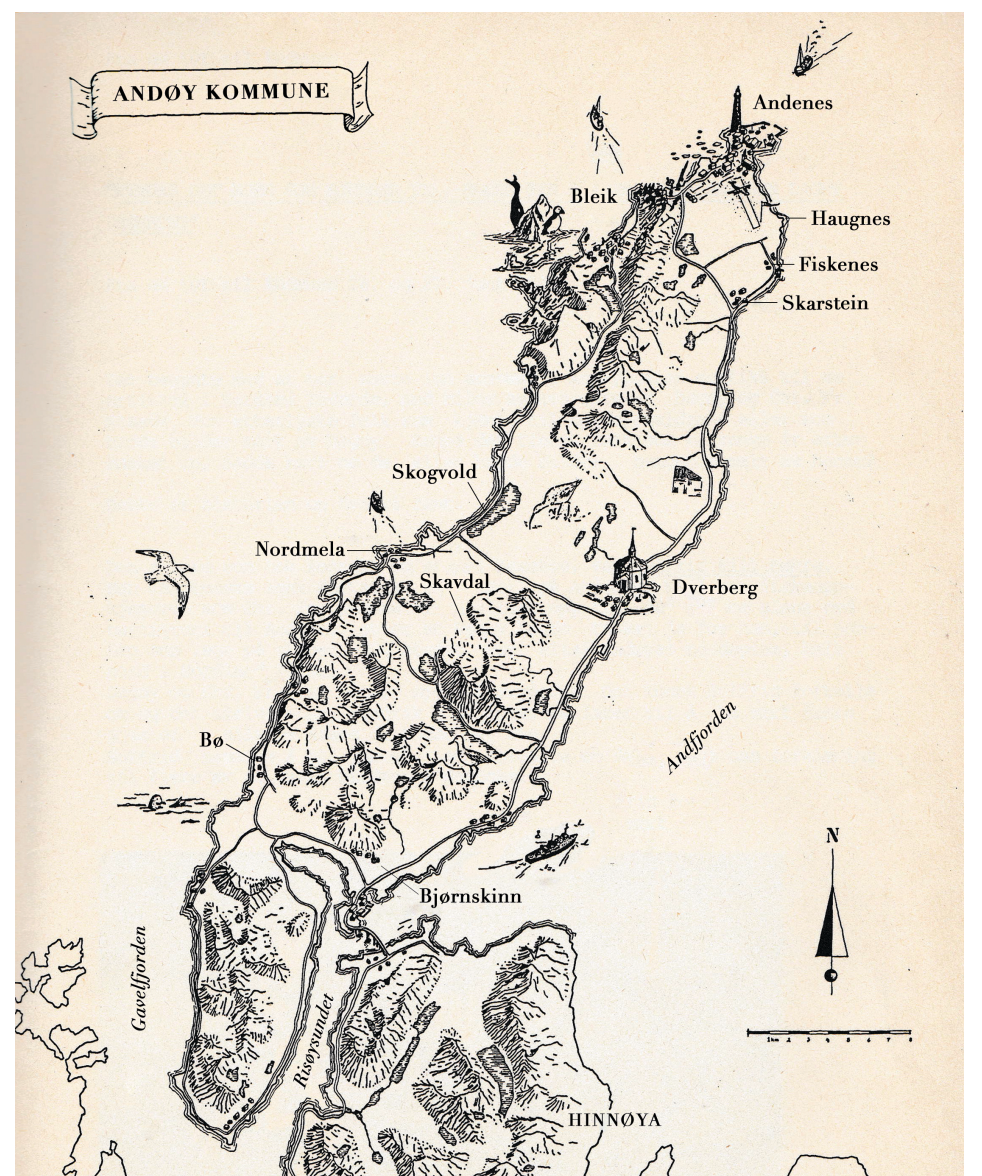

Kart over Andøy kommune. Illustrasjon: Trond Kanstad, tilpasset av Tidsskriftet

Covid-19-epidemien omtales nå av Verdens helseorganisasjon som en pandemi (1). Den er sammenliknet med spanskesyken (1918-19) og de andre store viruspandemiene på 19oo- og 20oo-tallet (2). Isolering av smittede og syke som tiltak for å hindre smittespredning var like aktuelt den gang som nå $(3,4)$. 


\section{Kommunelegen}

Under utbruddet av spanskesyken var Christian Fredrik Rossow (1871-1948), min oldefar, kommunelege på Andenes i Andøy kommune. Han virket som kommunelege på Andenes i tolv år fra 1912 og har etterlatt seg en håndskrevet bok (5) tilegnet sin kone, malerinnen Dagny Rossow (1873-1953). Også hun bidro aktivt under denne epidemien. De ble selv begge syke av infeksjonen.

Hans øyenvitneskildring er et tidsdokument. Møtet med pandemien den gang ga støtet til etablering av en lokal Røde Kors-forening (1919) og bygging av en sykestue på Andenes (1923) for å ta hånd om syke. Foreningen feiret sin 10o-års dag i august 2019.

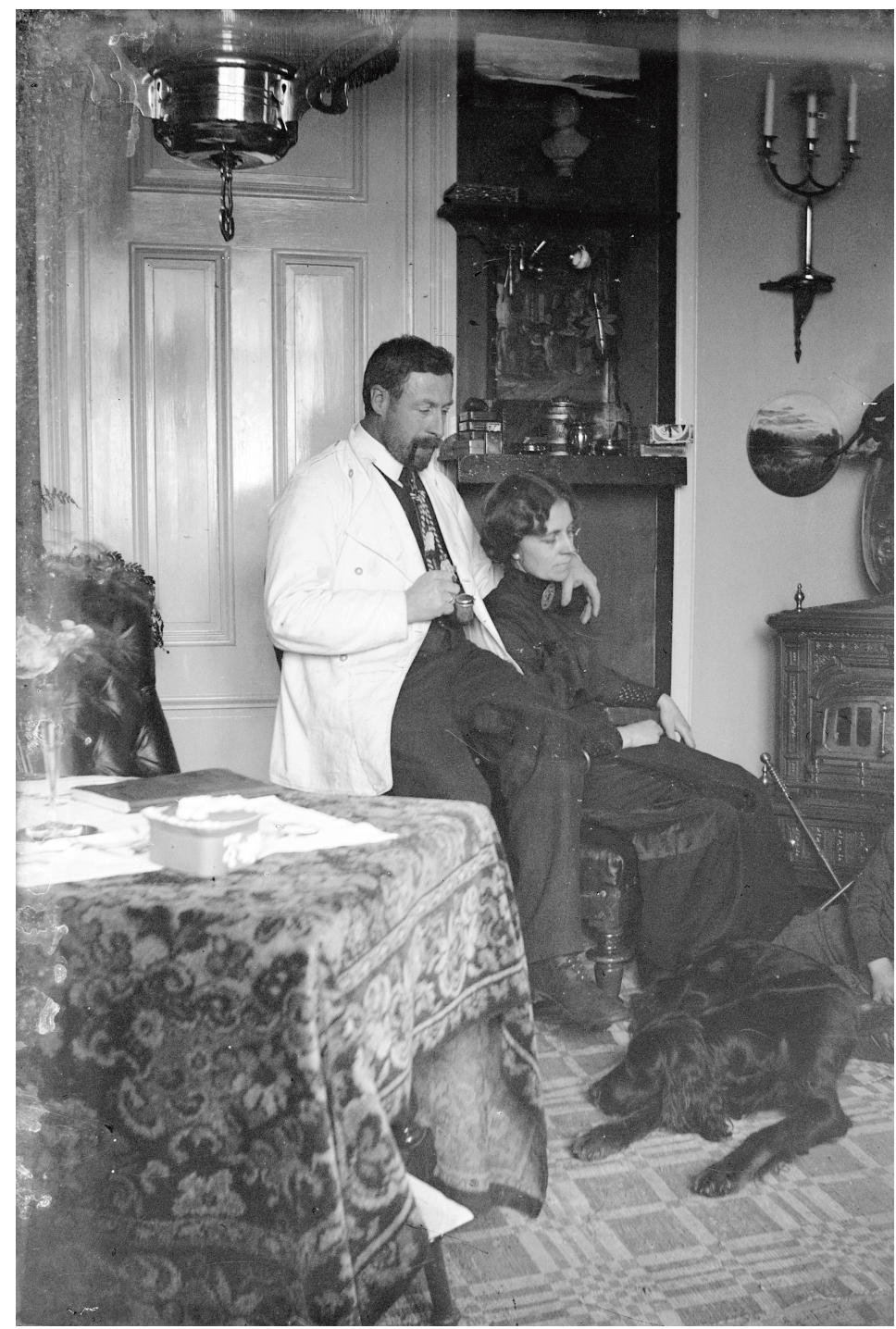

Christian Fredrik og Dagny Rossow, Andenes ca. 1918. Foto Magdalene Norman/SørTroms Museum

\section{Det kom et skip...}

Spanskesyken kom til Andenes fra Harstad med lokalbåten, dampskipet D/S Andenæs VDS (Vesteraalens Dampskibsselskab) 21. juli 1918. Dagen etter ble de første syke meldt. Disse hadde vært om bord under anløpet (6).

Rossow skrev slik om møtet med epidemien (med mine tilføyelser/kommentarer i parentes):

«Utover sommeren 1918 begynte da spanskesyken at gaa dernord, -vi hadde tidligere hørt om dens herjinger sydpaa og haabet $i$ det lcengste at gaa fri for den, -saa langt utenfor folkeskikken, som vi var. Men en dag fik jeg telegram om at komme om bord i D/S Andences, da der var fuldt op av syke om bord. -Jeg maatte ta medicin med. - Det var et sørgelig syn som møtte mig der, $i$ alle lugarer laa syke enkelte riktig daarlige ogsaa. Av skibsbetjeningen laa $3 / 4$, saa de ikke hadde tilstrekkelig mandskap 
engang. Den medicin jeg hadde med, forslog ikke, saa der maatte hentes mer. Kapteinen ønskede at jeg skulde følge med til Harstad, hvilket jeg ogsaa gjorde. Jeg kom tilbake nceste dag.

Med D/S Andences kom ogsaa Eivind og Bjarne (sønnene) fra Oslo, -heldigvis var begge to friske. Det var en stor glcede i familien av den grund.

Krigen (1914-18) rasede imidlertid endnu, og det syntes som vor nøitralitet ogsaa den gang stod i fare. Mine raadsmøter skulde ikke begynne før 3 .die august og vare til midten av september, saa jeg hadde den bedste del av sommeren hjemme paa Andenes, men jeg maatte vare forberedt paa lidt av hvert, da det naarsomhelst kunde bli kritisk.»

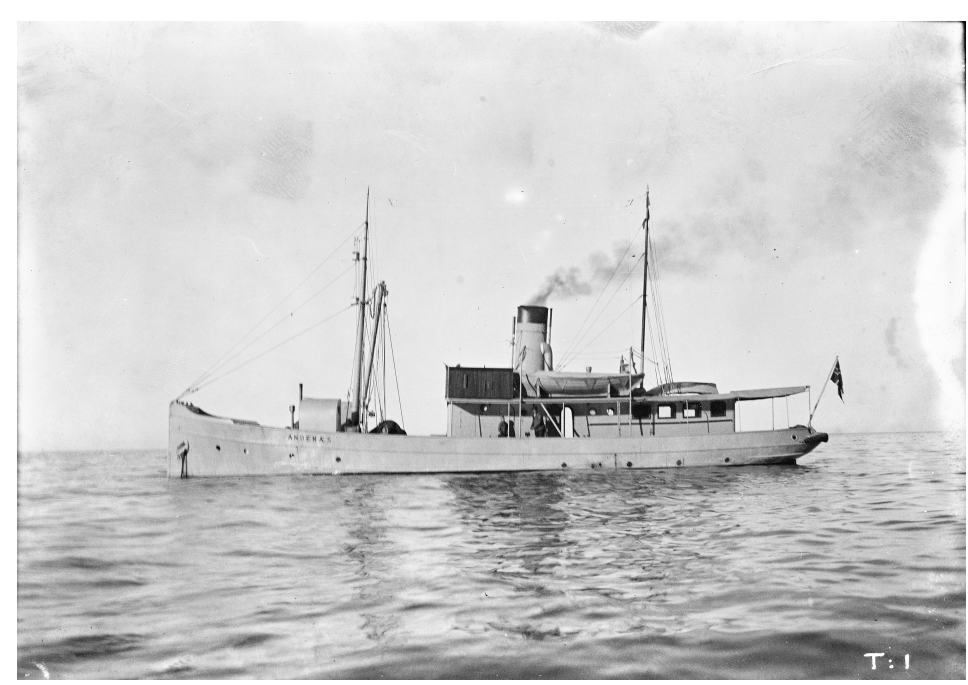

D/S Andences. Foto: Lofotmuseet-Museum Nord

\section{Smittet}

«Tiden gik imidlertid,- og spanskesyken viste sig baade her og der. -Saa en dag da vi-barna ogjegholdt paa at kaste skotthyll, blev jeg hentet til Haugnes - en $4 \mathrm{~km}$ `s vei. -Jeg tok cyklen og alt gik fint og vel, til jeg var kommen hjem. - Da fik jeg pludselig frysninger og efterpaa en voldsom svetning, saa det dryppet av ansiktet mitt. - Barna vilde at jeg skulde fortsette at kaste skotthyll - men det klarte jeg nok ikke. -Baade mor (hans kone Dagny Rossow) og Kiil (vcereier Jens Anton Kiil 1847-1930), som fik se mig staaende slik paa trappen, mente, jeg hadde kjørt for fort, - men det var ikke tilfceldet! Jeg forstod, at jeg hadde faat spansken, og stod bare og spekulerede paa, hvad jeg skulde gjøre. -Jeg bad mor (Dagny) sette paa kogende vand og bød Kiil med paa en toddy. - Da maatte han le, da det jo var saa varmt. -Men vi fik toddy og jeg drak 3 store glas efter hverandre. Sa gik jeg op og lagde mig. Temperaturen var 41 grader, og jeg fantaserede visst ganske bra om natten, -men nceste dag var temperaturen gaatt ned til 38 og om aftenen var den normal. - Dagen derefter var jeg oppe igjen, saa jeg slap heldig fra den.»

\section{«Fru doktor»}

«--Noen dager senere maatte jeg reise til Elvegaardsmoen (militcer øvingsplass i Narvik hvor Rossow var divisjonslege) og der blev jeg til 18. november! -En lang og besvarlig tjeneste. Mens jeg var paa moen, skulde jeg egentlig ha holdt vikar, men det var ingen mulighet for noen saadan, saa vi kom op $i$ en noksaa penibel situasjon, da spansken begynte at herje voldsomt. - Riktignok var der apothek, hvor man kunde faa de almindeligste mediciner, men det var jo ikke nok.-Men distriktslagen,- $d r$. Krogstad - paa Dverberg hadde lovt at holde kontordage 1-2 ganger om uken, og det var jo bra. Dessverre kunde han ikke klare dette, da paakjenningen i Dverberg og Bjørnskinn blev for stor for ham. - Og saa blev det 'fru doktor' (Dagny Rossow) som maatte ta det tyngste løft og gaa rundt og hjelpe de syke, og det var mange steder den gangen.

Spanskesyken kom til Andenes fra Harstad med lokalbåten

Baade i rorbuer og i hjemmene la fullt op av syke, og noen sykepleierske ellers fantes ikke. - Men 'fru doktor' organiserede hjelpen efter samraad med Frelsesarmeens offiserer og et par andre villige 
kvinder-og paa denne maaten kom de efter mange vansker gjennom denne fryktelige epidemi. - Det varjo mange dødsfall ogsaa. (...)

Selv 'fru doktor' og hushjelpen blev syke og maatte til sengs, og der blev da saa stilt paa doktorgården, at fru fyrvokter maatte bort og spørge hvorledes det var. - Forskrekkelsen blev jo stor, da hun fik se begge disse syke. Men hun var et straalende menneske. Hun hjalp dem da paa bedste maate med at lave lidt mat og vaske og stelle dem» (5).

\section{1. og 2. bølge-behov for isolering}

Epidemien kom i flere bølger, først i juli 1918, med første registrerte tilfelle 22. juli. Etter få dager var 50-6o blitt syke, spredt over hele fiskeværet. Først åtte dager senere nådde epidemien de nærmeste bygdene, Haugnes, Fiskenes, Skarstein og Bleik. Denne første tiden forløp angivelig uten dødsfall lokalt (6). Men allerede 16. og 17. august kom de første dødsfallene. Det var på Bø, hvor en 43 år gammel kone og hennes ett år gamle datter døde, med én dags mellomrom.

Deretter, i september, kom en mer ondartet form, med flere dødsfall. Andøyposten skrev i forbindelse med dette 4. oktober 1918: «Spanskesyken synes ogsaa her at spre sig i uhyggelig grad. Visstnok er her hittil ikke forekommet saa mange dødsfald, men der skal vare en hel del folk syke både her på stedet (Andenes) og i bygden. Foreløpig har helseraadet påbudt lukket de forskjellige forsamlingshuser, og det er ikke usannsynlig at ogsaa skolerne maa lukkes.»

11. oktober 1918 skriver avisen: «Den spanske syke raser nu ganske voldsomt. I nar sagt de fleste hjem er der sykdom, og ikke saa faa dødsfald».

18. oktober: «Med spanskesyken er det lidt bedre her paa stedet, men den raser fremdeles $i$ bygden, scerlig i Bjørnskinn, hvor der paa kort tid har forekommet flere dødsfald, scerlig blandt kvinder» (5).

Helserådet forbød i oktober de fleste offentlige sammenkomster, det ble bare gjort unntak for skolene og «alminnelig gudstjeneste». Om det at skolene ikke ble stengt, skriver distriktslege Krogstad: «At ikke ogsaa skolerne blev lukket skyldtes, at der var forholdsvis faa tilfcelder av sygdommen blant barn». Men 12. desember dette året ble også skolen på Andenes stengt. I skoleprotokollen for dette året står det: «Helseraadet paabød skolens lukning til jul» (6).

\section{Mangel på helsepersonell}

I enkelte familier var alle syke og trengte hjelp utenfra. Men det store antallet sykdomstilfeller «spredd rundt i 3 sogn» gjorde at det ikke var lett å få tak i forsvarlig hjelp til stell av de syke. Dagny Rossow, min oldemor, rykket derfor inn en annonse i Andøyposten 22. november 1918 med følgende opprop:

"(...) I denne tid, da sykdom herjer i ncer sagt hvert hjem, trænges der mange steder hjelp til at pleie og stelle de syke. Er der nogen der av sit gode hjerte vil hjelpe og lindre nøden, kan de melde sig til doktor Rossow, som vil anvise hvor det helst trænges. Var ikke bange for smitte, det bør ikke holde nogen tilbake for at hjelpe de syke stakler i denne forfardelige tid» (6).

\section{3. bølge - juletrefest som smittespreder}

Romjula 1918 ble vestsiden av Andøya rammet av en tredje smittebølge. 26. desember ble det avholdt en juletrefest på Nordmela hvor så godt som all ungdom fra bygdene Nordmela og Skogvold deltok, også en sønn og tjenestepike på gården Skavdal. Distriktslege Krogstad nevner i medisinalberetningen for 1918 at folk fra denne gården ikke hadde vært hos noen eller hatt besøk av andre de siste 14 dagene før jul. 28. desember ble de første syke, med høy feber og hoste. Hos sønnen ble det påvist «hoste med sparsomt, seigt, rustbrunt slim». Hos han "fandtes en utbredt bronchit over begge lunger, hos tjenestepigen kunde intet fysikalsk paavises». Samme ettermiddag ble det fra Nordmela meldt at praktisk talt alle som hadde vært til stede på juletrefesten var blitt syke (6). 


\section{Sykdomsbildet}

Distriktslege Krogstad mente på bakgrunn av sykdomsutbruddet etter juletrefesten at sykdommen hadde en inkubasjonstid på 48 timer. Han skriver ellers i medisinalberetningen fra dette året om symptomene:

"Hos de fleste opptraadte sykdommen ganske akut- som den var kastet over en, og ytret sig med temmelig sterk hodepine, dedolationer (muskelsmerter), rygsmerter, hceshet, snue og hoste med eller uten bronchit, og den syke maatte som regel straks gaa til sengs. Ofte ogsaa nceseblødning. I almindelighed varte saa sygdommen 8-14 dager, men patienterne følte sig ofte slappe og matte i flere uker efterpaa. Ikke sjelden optraadte der en generende svedning som kunde holde sig 2-3 maaneder efterat vedkommende var arbeidsdyktig» (6).

Helseraadet paabød skolens lukning til jul

Krogstad nevner også at lungebetennelse ofte opptrådte i forbindelse med influensaen og ellers lettere ørebetennelser som gikk tilbake uten behandling. I tillegg var det noen få gastrointestinale tilfeller av influensaen med akutt diaré. Disse forløp relativt lett og varte i 3-4 dager (6). Han skriver videre at «umiddelbart $i$ tilslutning til influenza har jeg set 4 tilfeelder av klinisk paaviselig lungetuberkulose. 2 av disse hadde tidligere havd tbc. Pedis, der var i god bedring, men i tilslutning til influenza optrådte en hurtig fremadskreden lungetuberkulose. Hos de 2 andre var der tidligere intet tegn paa tuberkulose» (6).

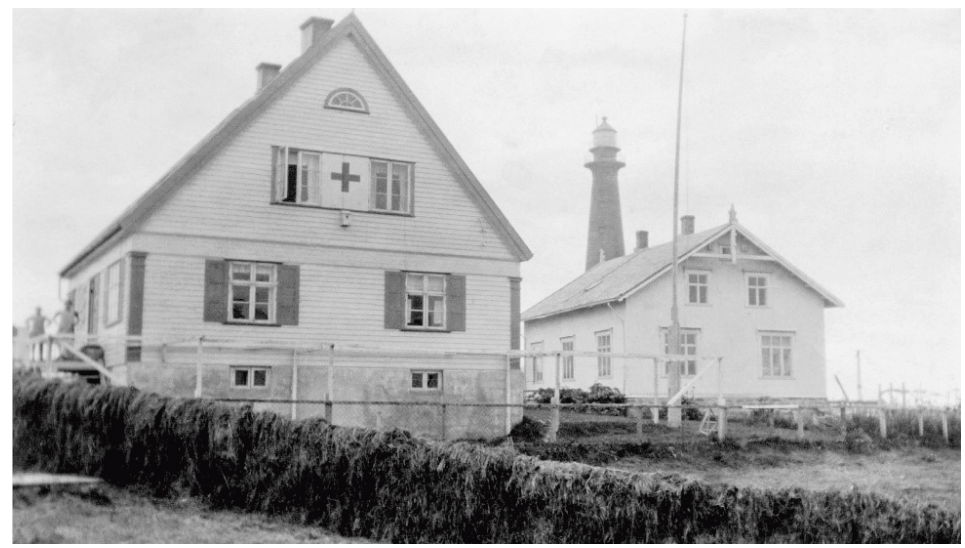

Røde Kors sykestue, Andenes. Foto: Sør-Troms Museum

\section{Sporløst borte}

Rossow skrev om avslutningen av epidemien i sin rapport for 1919: «Den forsvant sporløst med aaret 1919s begyndelse, $i$ det der ikke er anmeldt mere end 3 tilfcelde» (5). For året 1918 var tallet på anmeldte influensasyke 549 .

Men han la til at «der optraadte imidlertid de første maaneder (1919) en del tilfcelder, som jeg har opfattet som eftersykdommer til denne lumske sykdom, saaledes svcekkelsetilstande av hjertet, nervøse lidelser av forskjellig art, hysteri, og melankoli, samtlige dog av forbigaaende natur» (5).

\section{Botemidler}

Effektiv medisin mot selve infeksjonen var den gang, som nå, fraværende. I nær alle hus skal det ha stått en boks tjære på ovnene da det ble påstått at tjæredampen skulle være både forebyggende og lindrende overfor spanskesyken. Noen mente også å ha tro på tobakk og mente at nikotin skulle ta knekken på «djevelskapen».

Smittespredning og anbefalte tiltak er påfallende like når vi sammenlikner dagens pandemi med spanskesyken for over 100 år siden

Flere mente også at konjakk hjalp mot sykdommen. Kuriøst er det at alkoholforbudet under 1. verdenskrig, som ved stortingsvedtak ble gjort permanent, ble opphevet av regjeringen i forbindelse med spanskesyken. Gunnar Knudsens (1848-1928) venstreministerium ble 
senhøsten 1918 massivt presset til å tillate at alle husstander, som et engangstilfelle, skulle få kjøpe en halvflaske brennevin uten resept - til behandling av spanskesyken (den løvlandske halvflaske)(7).

\section{Lokal dødelighet}

I distriktslegens medisinalrapport fra 1918 skal «influenza» være oppgitt som dødsårsak i 16 tilfeller. Hvis vi går ut fra at antallet registrerte influensatilfeller (549) er riktig, gir det en dødelighet på 2,9 \%. I kirkebøkene er riktignok spanskesyke angitt som dødsårsak i 24 tilfeller dette samme året. En mulig forklaring på forskjellen i oppgitt dødelighet kan skyldes at noen av de som døde av spanskesyken og ble begravet i Andøy, ikke døde der. De kan ha blitt brakt tilbake til hjemstedet og stedt til hvile der (6). Folketallet på tettstedet Andenes var i 1918 ca. 1500 , og det var syv registrerte døde av epidemien. Folketallet i hele Andøy var ca. 4770 (1910).

Av de 16 registrerte døde av spanskesyken i hele kommunen, var seks kvinner og ti menn. Halvparten av mennene som døde, var 20-30 år. Kvinnenes alder var jevnere fordelt. To av de døde kvinnene var under 16 år, men ingen var over 60 år (6).

\section{Tiltak etter epidemien}

Rossow ville bruke erfaringene fra epidemien til å bedre mulighetene for mer effektiv isolering og behandling av syke. Han skrev videre om dette:

«Belcert av erfaring efter spanskesyken, difteriepidemier og alle de større og mindre ulykker, samt de mange syke i rorbodene, -begynte jeg at ta op spørgsmaalet om en sykestue paa Andenes. - Laget noen tegninger og sendte dem ind til uttalelse. - Begyndte med basarer, efter først at ha laget en voldsom propaganda for saken. Og pengene strømmede ind $i$ massevis, saa jeg allerede $i$ løpet av sommeren hadde 40oo,-.

- Saa blev der efter fru Keilhaus (Louise Keilhau, norsk lcerer, fredsaktivist og ledende medlem av Norges Røde Kors, 1860-1927) forslag dannet Andenes Kreds av Røde Kors, som skulde fortscette arbeidet med sykestue. Jeg hadde den cere at vcere formand i denne kreds i den tid jeg var paa Andenes. Samtlige styremedlemmer var sterkt interesserede, saa der blev fester og basarer og tilstelninger av enhver art, for at faa den nødvendige kapital; men det var langt frem. - En ansøkning til fylket om et større bidrag - anbefalet av herredsstyret - blev ikke indvilget av budgetmessige hensyn! - Med andre ord, vi maatte selv arbeide med saken og lacgge byrdene helt og holdent over paa Andøyas befolkning» (5).

En lokal forening av Røde Kors ble altså dannet på Andenes i 1919 og ny sykestue stod ferdig i februar 1923. Norges Røde kors hadde da gitt tilsagn om et rentefritt lån på 30 ooo kroner. Lokalbefolkningen på Andøya hadde selv samlet inn 10 ooo kroner (5).

\section{Tankekors}

Smittespredning og anbefalte tiltak er påfallende like når vi sammenlikner dagens pandemi med spanskesyken for over 100 år siden. Hva mangler i dag som kan forbedres til neste gang?

Takk til Svein Spjelkavik, May-Britt Johansen og Rigmor Anna Dava for å ha bidratt med kildemateriale og lokalhistorie og til konservator Børge Evensen ved Sør-Troms Museum for utlån av bilder og tillatelse til gjengivelse av disse.

LITTERATUR:

1. Dagsrevyen NRK. 11.3.2019. https://tv.nrk.no/serie/dagsrevyen/201903/NNFA19031119 Lest 25.3.2020.

2. Aavitsland P. Koronavirusepidemien vil ramme Norge. Tidsskr Nor Legeforen 2020; 140. doi:

10.4045/tidsskr.20.0077. [PubMed][CrossRef] 
3. Folkehelseinstituttet. Nytt koronavirus (coronavirus) 2019-nCOV - fakta, råd og tiltak. https://www.fhi.no/sv/smittsomme-sykdommer/corona/2019 Lest 25.3.2020.

4. Ording O. Så smittsomt er det nye coronaviruset. VG 1.1.2020.

https://www.vg.no/nyheter/utenriks/i/7oggzw/saa-smittsomt-er-det-nye-coronaviruset Lest 25.3.2020.

5. Rossow CF. Minder fra barndom til alderdom 1873-1943. Håndskrevet dokument.

6. Solhaug O. Da spanskesyken herjet. And-Ungen 1998.

7. Hem PE, Hem E. Et regelverk fullt av smutthull - legenes reseptrett i forbudstiden 1916-26. Tidsskr Nor Legeforen 2012;132: 2636-40. [PubMed][CrossRef]

Publisert: 27. mars 2020. Tidsskr Nor Legeforen. DOI: 10.4045/tidsskr.20.0216

(C) Tidsskrift for Den norske legeforening 2020. Lastet ned fra tidsskriftet.no 